\title{
Injury by Fire and Bark-beetle Attack.
}

$\triangle$ BOUT a quarter of a century has elapsed since bark-beetle infestations following fires in coniferous forests came under serious consideration outside European countries. The ideas and opinions then expressed, based admittedly on investigations which still had to stand the test of future corroboration, were at first treated with more or less open scorn by the professional forester both in the United States and in India, the two countries where attention was first paid to the matter. In the former country the commercial lumberer also regarded the scientific worker as a faddist. Of recent years, opinions have undergone a drastic change in both countries, and the present position and opinions held on this important subject are due to the patient work of the entomologist. In India, owing to the difference in climate in the plains, the matter is not confined to the coniferous forests of the mountainous regions, but has to be considered in its relation to the forests of broad-leaved deciduous species. The problem here, however, save perhaps in the native States, has not been complicated during the period alluded to above by the operations of the lumberer and his felling methods in the forest.

Recently two small but important monographs have been issued in the United States. The first, entitled "Preliminary Studies on the Relation of Fire Injury to Bark-Beetle Attack in Western Yellow Pine (Pinus ponderosa)," by Messrs. J. M. Miller and J. E. Patterson (Journal of Agricultural Research, Washington, April 1927), and the second, "The Relation of Highway Slash to Infestations by the Western Pine Beetle in Standing Timber," by J. E. Patterson (U.S. Dept. of Agric., June 1927). The latter paper has a closer connexion with the danger of infestation from slash in the neighbouring standing forest than with previous damage by fire.

The literature available on the effect of fire in the pine forests of the Pacific slope region is considerable. One phase, the effect of bark-beetle infestations following the fires, has previously received scant treatment. It has been generally recognised that there is a direct relation between fire injury and later insect damage on burned-over, areas. Two types of loss are involved-destruction of the marketable value of fire-killed trees by wood-boring insects, and the actual killing by bark beetles of trees that survived the fire. Such damage follows as a result of the sporadic local increase of bark-beetle population within the fire area, which can be explained only by the assumption that numbers of beetles fly into the area from the surrounding forest. The authors hazard the following hypothesis: "Because of fire injury certain trees become especially attractive to the beetles. The physiological basis of this attraction is but vaguely understood. The odour of firescorched foliage and cambium may be an attractive influence, or the insects themselves may possess an instinctive ability to select those trees in which sap resistance has been weakened by fire injury, but whatever the influence, it is evidently a very strong one of determining the behaviour of Dendroctonus beetles." The explanation would seem to rather lie in the unerring instinct possessed by the bark beetles, and one may add to these many species of the longicorns and buprestids, which leads them to choose out trees the vitality of which for whatever reason is impaired for the time being. For example, these groups of beetles exhibit the same instinct in infesting wind-blown or snow-broken trees. The heavy windfalls which occurred near Gerardmer in the Vosges in the late autumn of 1903 , to quote but one European example, were followed by a heavy concentration of bark beetles on the wind-blown trees the following year. So serious was this attack that a considerable area of forest had to be felled before it was stamped out.

The various aspects of the inter-relation of fire and insect damage raise many questions that are pertinent to the protection of pine forests. The authors set themselves the following questions: What type, and what degree of fire injury make trees attractive to bark beetles? Are such trees capable of recovery if not attacked by insects? Do bark beetles "breed up' in fire areas, increasing their numbers to an epidemic status, and then become aggressive in uninjured trees in and around burned areas? As they correctly state, the answers to these questions, of extreme importance to the forester, can only be obtained by a careful study on the ground.

The monograph by Messrs. Miller and Patterson is a most valuable piece of work and merits the careful study by all interested in this matter. Briefly, the authors' conclusions are as follows: Forest fires of sufficient severity to scorch the bark and foliage of yellow pine trees produce types of injury which make certain trees especially attractive to the Western pine beetle. Many trees which have been only moderately injured by the fire and are apparently capable of recovering, are attacked and killed by the beetles after a fire of this character. The attraction of fireinjured trees often causes a concentration of beetles within a burned area which lasts for one or two seasons following the fire. This attraction may extend for a distance of two or three miles from the burn. The concentration of bark-beetle attacks in fire-injured trees within a burned area does not develop into an epidemic condition. The loss from barkbeetle attacks in trees not injured by the fire either within the area of the burn or in the surrounding forest is not materially increased as a result of this concentration. Trees which have been defoliated by the fire are not favourable breeding places for the beetles, the resultant mortality amongst the latter, owing to the abnormally moist condition of the inner bark, being high. Finally, the authors' studies show that fires can be of but little benefit in reducing beetle losses through killing the beetles unless the fires are sufficiently severe to kill the trees. They add, in conclusion, "bark beetles supplement and increase timber losses initiated by forest fires, while fires have but little influence in permanently increasing the losses caused by bark beetles.'

The second brochure here under review, by $\mathrm{Mr}$. Patterson alone, deals with the inter-relation of slash (lop and top, etc., of trees) and insects, especially bark beetles and borers. In the United States three types of slash are recognised, and the definition is not without its value in Great Britain, namely, logging slash, the waste left in bulk on the ground after logging; line slash resulting from clearing roads, power lines and telephone lines (occurring in narrow strips); and wind-blown slash, i.e. wind-blown or snow-broken trees left unremoved. Both foresters and lumbermen have come to recognise, for the matter has been widely discussed, that if only to minimise the danger of fires originating in the slash and spreading into valuable standing forest, its disposal is advisable. The problem is further complicated by insect infesta. tion, the green material being in the condition most suited to the beetles for oviposition.

The study undertaken by Mr. Patterson was to determine definitely whether the insect infestation of the slash threatened the value of adjacent standing

No. 3050, VoL. 121] 
timber, the species investigated being in line slash of the Western yellow pine in Southern Oregon. The following are the conclusions arrived at. The line slash of this species is very attractive to the bark beetle (Dendroctonus brevicornis). The attack in the slash is not so heavy as in mature standing timber. The broods developing in slash are characterised by abnormal mortality (64 per cent. increase of beetles as compared with 135 per cent. in adjacent standing timber). Bark beetles from the surrounding standing timber are attracted to the slash at the time of attack, and a temporary concentration of infestation occurs in its immediate vicinity. Normal distribution of the infestation is resumed within the year. The concentration in the slash and the resulting beetles therefrom have little influence on infestations in the surrounding forests. Concluding, the author considers that the infestation of line slash by this beetle is not a serious menace to neighbouring mature timber, and may be disregarded when the problem of slash disposal is under consideration.

These two monographs merit the consideration of those interested in these matters. They exhibit a praiseworthy amount of careful research and experiment, undertaken in the forest, yielding results of practical utility.

\section{Fisheries and their Products.}

THE twentieth meeting of the Conseil Permanent International pour l'Exploration de la Mer took place in May 1927 at Stockholm. The report ${ }^{1}$ marks the twenty-fifth anniversary of the foundation of the Council, which, mainly through the efforts of Sir John Murray, Prof. Cleve, Dr. Otto Petterson, and Dr. Fridtjof Nansen, owed its existence to the initiative of the late King Oscar II. of Sweden, who summoned in 1889 at Stockholm the first of the two conferences leading up to the foundation of the Council in 1902. The programme of international exploration had for its object the study of the hydrography and biology of the North Atlantic, North Sea, and Baltic, including statistical and industrial problems. With the recent inclusion of Italy, the Mediterranean is now added and fifteen countries are involved.

During the twenty-five years in which the Council has been in existence much work has been done, but most of the problems are so large that they need many years to show any results. Even now, however, in the infancy of the researches, definite results and promises of important results are seen. Direct research on fishes (especially food fishes, but also others indirectly related), with particular reference to their life histories, migrations, fluctuations, food, and environment, come first, and side by side the hydrography and plankton work with bottom sampling. At the same time statistical investigations, comparisons of various nets and methods of fishing, as well as research into the over-fishing of certain areas, are in progress, whilst the work on the whale fisheries is planned to fit in with that of the Discovery Expedition.

The hydrographers, continually active in all the countries concerned, maintain regular observations on temperatures and salinities, with special studies of currents and ice conditions. Plankton work in connexion with hydrography and its relation to fish food is undertaken in most of the countries, bottom sampling chiefly in the southern North Sea area. The most important fishes investigated are herring, cod, haddock, and plaice. A large amount has been done on the herring, in the North Sea, particularly the young stages (the main problems of its life history now being known), with regard to races, migrations, and fluctuations. Great Britain, France, Denmark, Norway, Sweden, Germany, and Poland all help in the herring work. The north-eastern area is mainly responsible for the cod. This includes sending specialists on board trawlers for the study of statistics, age, and food. A result of this is found in the comparison of fish from the coast of Finmarken and from the White Sea, showing that they belong to a common stock. Research on the haddock, chiefly in the southern North Sea area, has resulted in important

1 Conseil Permanent International pour l'Exploration de la Mer, Rapports et Proces-Verbaux des Réunions, vol. 45. (Copenhague: Andr. Fred. Høst et fils, 1927.) work, carried on at Aberdeen, on age determinations ; whilst the plaice, also in this area and in the northwestern area, has been investigated particularly in Denmark and the Baltic. It is reported that there is a very large increase in the Baltic fishery in the last few years, and the red tunny has appeared in numbers in the North Sea in connexion with the herrings. Work on salmon and sea trout, together with the study of river pollution, is also being carried on.

The general conclusions to be drawn from this report are that the main facts relating to the spawning areas, life histories, food, age, and migrations of the most important food fishes (especially plaice and haddock, and to a less extent, herring and cod) are now known, and there is a general knowledge of hydrographical data, plankton distribution and bottom communities, especially in the North Sea, all of which form a foundation on which to carry on the enormous amount of detailed work still to be done. The statement of the North Sea Combined Committee that "there are certain features in the life histories of our most important commercial fishes . . . which are still obscure," whilst suggesting special attention to these, only voices the opinion of the Council as a whole, when recommending continuance of the existing programme in all areas and in all sections rather than beginning work on new lines.

A large amount of important and interesting information dealing with sea fisheries and suggestions for their improvement, with regard especially to those products which largely enter into the food of the people of the British Isles, has been published in a recent report of the Imperial Economic Committee on Marketing and Preparing for Market of Foodstuffs produced within the Empire. ${ }^{2}$

The main fishing grounds are almost wholly confined to water of less than 200 fathoms depth, situated in all parts of the Empire, but the North Atlantic and the North Pacific are the only two parts of the world where the fishing industries have been developed on a large scale, the North Atlantic being the most important. There is no evidence pointing to a shortage in the total fish supplies of the world, although the amount of fish on the fishing grounds may vary and some of them may have been overfished. There are many valuable grounds at present only partially worked, because they are difficult of access and the present methods of preserving are not suitable for prolonged sea voyages. Nevertheless, the tendency is to go farther and farther afield.

In the British Isles, the demand is chiefly for 'white fish,' that is to say, such fish as cod, whiting, and sole, as distinct from 'pelagic' fish such as herring and mackerel, the two divisions representing fish of different habit and therefore requiring an

2 "The Report of the Imperial Economic Committee on Marketing and Preparing for Market of Foodstuffs produced within the Empire." Fifth Report: Fish. (London: His Majesty's Stationery Office, 1927.) 